\title{
Martingales Property in Albania Exchange Market
}

\author{
PhD. Candidate Rozana Liko \\ PhD. Candidate Artion Kashuri \\ Department of Mathematics, Faculty of Technic Sciences, University "Ismail Qemali" Vlora, Albania \\ Email: rozanaliko86@gmail.com/ artionkashuri@gmail.com
}

\section{Doi:10.5901/ajis.2016.v5n1p93}

\section{Abstract}

The aim of this paper is to test whether the Albanian exchange rate market is weak form efficient by studying the statistical behavior of daily Euro/All and USD/All exchange rate during the period January 05, 2010 - April 30, 2015, which are the most influential currency in Albania market. The study seeks to examine whether this currencies follow each a martingale. The unit root tests, and variation ratio test are used. The various analytical tests implemented in the study provide evidence of non martingale property of exchange market in Albania.

Keywords: Weak form efficiency, Martingales, Unit root test, Variation ratio test, Serial correlation, Exchange rate return.

\section{Introduction}

The purpose of this paper is to determine whether the foreign exchange market is weak form efficient by studying the statistical behavior of two daily foreign currencies against Lekë. The interesting of predicting returns or stock prices start early in the literatures, since Fama (1970) revealed his work. Early studies, concluded that a martingale or random walk was a good model for predicting the future price or value, i.e. the best forecast of the future price was the current price. Some requirement of efficiency are, the presence of a unit root process, the increments are random and uncorrelated, long term persistence of shocks etc. (Azar S. A, 2014). Especially, market efficiency implies zero serial correlations in exchange rate changes (Lee H. Y., Sodoikhuu K., 2012).

Numerous studies have been made on the behavior of exchange rates under the float. Since Lo and MacKinlay (1988) proposed a variance ratio (VR) test, this procedure has been widely used and has endure many improvements for testing market efficiency and return predictability (Phillips P. C. B., JIN S. 2014). Meese and Rogoff (1983) have shown that the structural models of exchange rate are well-approximated by a random walk in out-of-sample forecasts. Liu and He (1991) applied the variance ratio test on five weekly nominal exchange rates series vis-a-vis US dollar over the sample period from 7 August 1974 to 29 March 1989 and rejected the random walk hypothesis at five percent significance level. Ajayi and Karemera (1996) on South Asian foreign exchange markets rejected RWH but found that rejection were not robust to heteroscedasticity. Vats $A$. and Kamaiah B. used both parametric and non parametric methods for studes the behavior of weekly return of eight currencies against Indian Rupee and reject the random walk hypothesis for US Dollar and Hong Kong Dollar, the result for Singapore Dollar are mixed and for other five currencies random walk hypothesis could not be rejected.

The paper is organized as follows: In the second section is given a short presentation of the methodology and data. In third section empirical results are analyzed. Section fourth conclusions.

\section{Methodology}

Main concern of a market is to give equal chance to each investitor. In this paper we investigate weak form efficient where the market reflects all public information, and can be described as a random walk process (or martingale). Numerous studies has led to the conventional that foreign exchange rates follow a martingale in the sense that future changes are unpredictable based on past exchange rate changes. This martingale behavior is consistent with weak-form market efficiency, and has been adopted by many researchers in modeling exchange rates. 


\subsection{Methodology}

Let $\left\{Y_{t}\right\}$ be a stochastic process, if $\Delta Y_{t}=Y_{t}-Y_{t-1}=\alpha+\varepsilon_{t}$, where $\boldsymbol{\alpha}$ is a constant and $\boldsymbol{\varepsilon}$ is the residue, such that $E\left(\varepsilon_{t}\right)=0, E\left(\varepsilon_{t} \varepsilon_{t-1}\right)=0$, than $\left\{Y_{t}\right\}$ is said to be a Random Walk.

If $\left\{\ln \left(Y_{t}\right)\right\}$ is a stochastic process, such as $\Delta \ln \left(Y_{t}\right)=\ln \left(Y_{t}\right)-\ln \left(Y_{t-1}\right)=\alpha+\varepsilon_{t}$, where $\alpha$ is a constant and $\boldsymbol{\varepsilon}$ is the residue, such that $E\left(\varepsilon_{t}\right)=0, E\left(\varepsilon_{t} \varepsilon_{t-1}\right)=0$, than $\left\{\mathrm{Y}_{t}\right\}$ is said to be an Exponential Random Walk (Rufino C. C. 2014). The most popular technic used to test the random walk hipothesis is the variation ratio test. Some conditions of the weak form efficiency are the presence of a unit root and that increment is random and uncorrelated. In this study we have use some parametric and non-parametric test described below.

\subsubsection{L-B Q test}

Ljung-Box Q statistic is a modified variation of Box - Pierce Q statistic used to test the joint hypothesis that the autocorrelation coefficients up to lag $\mathrm{k}$ are equal to zero.

This test is defined as

$$
\mathrm{Q}=\mathrm{N}(\mathrm{N}+2) \sum_{\mathrm{i}=1}^{\mathrm{k}} \frac{\rho_{\mathrm{i}}^{2}}{\mathrm{~N}-\mathrm{i}} \sim \chi^{2}(\mathrm{k})
$$

\subsubsection{Run Test}

Run test (Wald Wolfowitz 1940) is a strong non-parametric test for detecting randomness of the series. The Z statistic is defined as

$$
Z=\frac{R-\bar{R}}{s_{R}}
$$

Where $\mathrm{R}$ is the observed number of runs, $\bar{R}=\frac{2 n_{1} n_{2}}{n_{1}+n_{2}}$ is the expected number of runs, and $s_{R}=$ $\frac{2 n_{1} n_{2}\left(2 n_{1} n_{2}-n_{1}-n_{2}\right)}{\left(n_{1}+n_{2}\right)^{2}\left(n_{1}+n_{2}-1\right)}$ is the standard deviation of the number of runs.

\subsubsection{Unit Root test}

In this study a battery of unit root tests are used as the well known ADF test (1979), Phillips-Perron (1988) test whose null hypothesis is a unit root and Kwiatkowski-Phillips- Schmidt-Shin (1992) test which the null hypothesis is stationary.

\subsubsection{Variation ratio test}

Lo and MecKinly (1988) variation ratio test is the most used econometric test for the null hypothesis of a martingale, which is robust to heteroskedastic standard errors. If the time series follows a random walk then the variance should be proportional to the same interval, i.e.

$$
\operatorname{VR}(q)=\frac{\operatorname{Var}\left(Y_{t+k}-Y_{t}\right) / k}{\operatorname{Var}\left(Y_{t+1}-Y_{t}\right)}
$$

The statistical test is given as

$$
Z_{1}(q)=\frac{V R(q)-1}{\phi(q)^{1 / 2}} \text {, where } \phi(q)=\frac{2(2 q-1)(k-1)}{3 q T}
$$

which follows an asymptotically $N(0,1)$ distribution, under the homoskedasticity assumption. The statistical test which is robust under heteroscedasticity is given as follows

$$
\begin{aligned}
& \mathrm{Z}_{\mathrm{q}}^{*}=\frac{\mathrm{VR}(\mathrm{q})-1}{\sqrt{\sum_{\mathrm{j}=1}^{\mathrm{q}-1}\left[\frac{2(\mathrm{q}-\mathrm{j})}{\mathrm{q}}\right]^{2} \delta}(\mathrm{j})} \sim \mathrm{N}(0,1) \\
& \text { where } \\
& \widehat{\delta}(j)=\frac{\sum_{t=j+1}^{n q}\left(Y_{t}-Y_{t-1}-\widehat{\mu}\right)\left(Y_{t-j}-Y_{t-j-1}-\widehat{\mu}\right)^{2}}{\left[\sum_{t=1}^{n d}\left(Y_{t}-Y_{t-1}-\widehat{\mu}\right)^{2}\right]}
\end{aligned}
$$

Chow and Denning (1993) extend the Variation ratio test by introducing multiple variation ratio test which is based on the maximum absolute value of individual variation ratio test

$$
\mathrm{Z}_{2}(\mathrm{q})=\max _{1 \leq \mathrm{i} \leq \mathrm{N}}\left|\mathrm{Z}_{\mathrm{q}_{\mathrm{i}}}^{*}\right|
$$




\subsection{Data}

The data consist of daily nominal exchange rate of two currencies, Euro and US Dollar (USD), against Albanian Lekë, which are the most influential currency in Albania. The time series cover the period from January 2010 to April 2015, i.e. 1344 observations for variables. The data set are obtained from Bank of Albania (http://www.bankofalbania.org/), which is the monetary authority of Albania. Bank of Albania applies a free fluctuation regime, which means that the currency is determined according to the foreign exchange markets. The series are logged and the returns are calculated as first differences of natural logs.

\section{Empirical Results}

\subsection{Statistical description of the data}

A visual inspection of the movements of currencies appears to be irregular and the mean returns are close to zero. All the series shows departures from Gaussian distribution. Indeed, Jarque-Bera test reject the null hypothesis of normality at significant value 0.001 . The volatility of returns suggest for heteroscedastic nature of this series, as showed by the ARCH test as well.
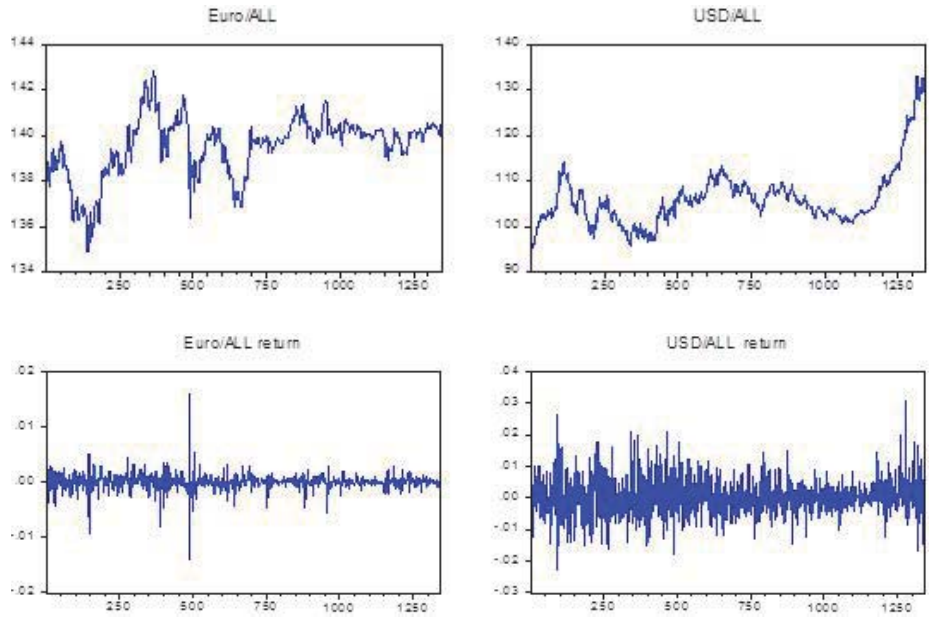

Figure 1. Line graph of daily nominal exchange rate (above) and returns (below) of Euro/ALL and USD/ALL from 2010 to 2015

Table 1. Descriptive statistics of exchange rate and returns of Euro/ALL and USD/ALL from 2010 to 2015

\begin{tabular}{|l|c|c|c|c|c|c|c|c|c|}
\hline Statistic & Mean & Median & Max. & Min. & St. Dev. & Skew & Kurt. & J-B & ARCH Test \\
\hline Euro/ALL & 139.517 & 139.86 & 142.84 & 134.86 & 1.32 & -0.82 & 3.75 & $182.35(0.000)$ & -- \\
\hline USD/ALL & 106.148 & 105.03 & 133.35 & 95.21 & 6.50 & 1.79 & 7.35 & $1780.9(0.000)$ & -- \\
\hline Euro/ALL return & $1.46 \mathrm{e}^{-5}$ & $7.12 \mathrm{e}^{-5}$ & 0.0159 & 0.014 & 3 & -0.315 & 31.24 & $44650.1(0.001)$ & $55.602(0.000)$ \\
\hline USD/ALL return & 0.00019 & 0 & 0.030 & -0.022 & 0.005 & 0.398 & 5.044 & $269.084(0.001)$ & $7.8802(0.000)$ \\
\hline
\end{tabular}

Note: Actual p-values are reported in brackets. The ARCH test of Euro/ALL return is calculated for 8 lag and ARCH test of USD/ALL test for 14 lag.

\subsection{Serial Correlation}

In Figure 2 and Figure 3 the results of Ljung-Box statistic on lag 10 are presented. As shown the null hypothesis of Euro/ALL return is rejected for $1 \%$ and $5 \%$ significant value. Different result is for USD/ALL return, the null hypothesis of zero serial correlation fails to reject. 


\begin{tabular}{|c|c|c|c|c|c|c|}
\hline Autocorrelation & Partial Correlation & & $A C$ & PAC & Q-Stat & Prob \\
\hline 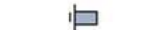 & り & 1 & 0.256 & 0.256 & 88.297 & 0.000 \\
\hline$\sqrt{1}$ & $\sqrt{1}$ & & -0.069 & -0.144 & 94.782 & 0.000 \\
\hline 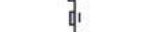 & 1. & 3 & -0.060 & -0.003 & 99.667 & 0.000 \\
\hline${ }_{1}$ & 中 & & -0.013 & -0.005 & 99.904 & 0.000 \\
\hline 中 & 中 & 5 & 0.012 & 0.009 & 100.10 & 0.000 \\
\hline d & 4 & 6 & -0.064 & -0.079 & 105.59 & 0.000 \\
\hline 1 & 1) & 7 & -0.033 & 0.009 & 107.09 & 0.000 \\
\hline 11 & 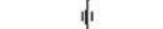 & 8 & -0.006 & -0.013 & 107.15 & 0.000 \\
\hline 1 & i & 9 & -0.009 & -0.013 & 107.26 & 0.000 \\
\hline 中 & 1) & 10 & 0.021 & 0.025 & 107.83 & 0.000 \\
\hline
\end{tabular}

Figure 2. Serial correlation of daily return of EURO/ALL

\begin{tabular}{|c|c|c|c|c|c|c|}
\hline Autocorrelation & Partial Correlation & & $A C$ & PAC & Q-Stat & Prob \\
\hline 小 & 中 & 1 & 0.008 & 0.008 & 0.0878 & 0.767 \\
\hline 中 & 中 & 2 & 0.010 & 0.010 & 0.2166 & 0.897 \\
\hline 11 & 1 & & -0.012 & -0.012 & 0.4125 & 0.938 \\
\hline di & d & 4 & -0.017 & -0.017 & 0.7890 & 0.940 \\
\hline p & 功 & 5 & 0.056 & 0.057 & 5.0134 & 0.414 \\
\hline$\sqrt{1}$ & $\sqrt{1}$ & 6 & 0.007 & 0.006 & 5.0770 & 0.534 \\
\hline 中 & 小 & & -0.003 & -0.005 & 5.0920 & 0.649 \\
\hline 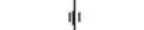 & 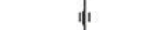 & 8 & -0.024 & -0.023 & 5.8833 & 0.660 \\
\hline ip & ip & 9 & 0.061 & 0.064 & 10.973 & 0.278 \\
\hline 15 & 15 & 10 & 0.034 & 0.030 & 12.494 & 0.253 \\
\hline
\end{tabular}

Figure 2. Serial correlation of daily return of USD/ALL

Applied run test on first differences of the logged data this test suggest the randomness of USD return, but not for Euro return.

Table 3. Run test of $\Delta \log Y_{t}$

\begin{tabular}{|l|c|c|c|c|}
\hline & Nr. of Runs & Mean & Nr. of Runs & Median \\
\hline Euro/ALL & 492 & $5.326(0.000)$ & 494 & $5.326(0.000)$ \\
\hline USD/ALL & 667 & $0.175(0.860)$ & 660 & $0.082(0.934)$ \\
\hline
\end{tabular}

Note: $z$-statistic are reported and p-values in brackets

\subsection{Unit root}

One requirement of the weak form efficiency (or martingale) is a unit root in the data series. Results of applied unit root test are display in table 4.

Table 4. Unit root test of In(EURO/ALL) and In(USD/ALL) from January 2010 - April 2015

\begin{tabular}{|l|c|c|c|c|}
\cline { 2 - 5 } \multicolumn{1}{c|}{} & \multicolumn{2}{c|}{$\operatorname{In}($ Euro/All) } & \multicolumn{2}{c|}{$\operatorname{In}($ USD/All) } \\
\hline & Level & First differences & Level & First differences \\
\hline ADF- test & -2.996477 & -25.79864 & -1.026937 & -36.15255 \\
& $(0.0355)$ & $(0.000)$ & $(0.7455)$ & $(0.0000)$ \\
\hline PP test & -2.897509 & -27.24623 & -1.099612 & -36.16000 \\
& $(0.045)$ & $(0.000)$ & $(0.7180)$ & $(0.0000)$ \\
\hline Kwiatkowski-Phillips-Schmidt-Shin test & 1.127697 & 0.031387 & 1.210691 & 0.149466 \\
\hline
\end{tabular}

Note: The $p$-values are reported in brackets

According to ADF test and PP test the series has a unit root in the level and no unit root in the first differences. This means that the series has only one unit root. Kwiatkowski-Phillips-Schmidt-Shin test statistic is greater that critical values for $1 \%, 5 \%$ and $10 \%$ in the level than the series is not stationarity but in the first differences is stationarity.

This means that the series are integrated of order one, i.e I(1), and the returns are not integrated, i.e I(0). 


\subsection{Variation ratio test}

To examine the correlation of increment the variation ratio and multiple variation ratio tests are employed and the results are presented in Table 5. The joint variation ratio test reject the null hypothesis of martingale for the Euro/ALL with $\mathrm{p}$ value 0.003 , but fails to reject the null hypothesis for USD/ALL. All individual variation ratio tests are insignificantly different from 1, which means that there is no significant serial correlation, except Euro for which the results are mixed.

Table 5. Variation ratio test of $\Delta \log (E U R O / A L L)$ and $\Delta \log (U S D / A L L)$ during the period January 2010 - April 2015.

\begin{tabular}{|c|l|l|c|c|c|c|}
\hline \multirow{2}{*}{ Chow-Denning Joint Variation ratio test } & \multicolumn{5}{l|}{ Individual Variation ratio test } \\
\cline { 3 - 7 } & Period & 2 & 4 & 8 & 16 \\
\hline \multicolumn{2}{|c|}{$H_{0}:$ Log(Euro/ALL) is a martingale } & Var.Ratio & 1.257 & 1.288 & 1.228 & 1.059 \\
\hline Max|z| & 3.341 & Std. Error & 0.077 & 0.157 & 0.223 & 0.275 \\
\hline df & 1343 & Z-statistic & 3.341 & 1.834 & 1.019 & 0.215 \\
\hline Prob. & 0.0033 & Prob. & 0.008 & 0.06 & 0.308 & 0.829 \\
\hline \multirow{2}{*}{ Chow-Denning Joint Variation ratio test } & Individual Variation ratio test \\
\cline { 3 - 7 } & Period & 2 & 4 & 8 & 16 \\
\hline \multicolumn{2}{|l|}{$H_{0}:$ Log(USD/ALL) is a martingale } & Var.Ratio & 1.008 & 1.012 & 1.028 & 1.106 \\
\hline Max|z| & 0.751 & Std. Error & 0.033 & 0.061 & 0.095 & 0.141 \\
\hline df & 1341 & Z-statistic & 0.242 & 0.201 & 0.294 & 0.751 \\
\hline Prob. & 0.916 & Prob. & 0.808 & 0.840 & 0.768 & 0.0452 \\
\hline
\end{tabular}

\section{Conclusions}

The purpose of this study is to examine the weak form efficiency (informational efficiency) of exchange market in Albania. Two currency are selected, daily nominal Euro/ALL and USD/ALL during the period January 05, 2010 - April 30, 2015.

The panel unit root test applied on the series suggest the presence of only one unit root which in consistent with the martingale hypothesis.

Variation ratio test more than one suggest positive correlation of returns. Multiple variation ratio test rejects the martingale hypothesis for Euro return but fails to reject this hypothesis for USD return.

\section{References}

Ajayi, R. A. and D. Karemera (1996) "A variance ratio test of random walks in exchange rates: evidence from Pacific Basin economics" Pacific-Basin Financial Journal Vol 4 77-91

Azar S. A. (2014): Martingales in Daily Foreign Exchange Rates: Evidence from Six Currencies against the Lebanese Pound, Applied Economics and Finance, Vol. 1, No. 1

Fama E. (1970), Efficient capital markets: A reviw of theory and empirical work, Journal of Finance, Vol. 25, No. 2, 383-417

Kirchgässner G. (2013), Wolters J., Hassler U.: Introduction to modern time series Analysis. 2-nd edn. Springer-Verlag, Berlin Heidelberg

Lee H. Y., Sodoikhuu K. ( 2012): Efficiency Tests in Foreign Exchange Market. International Journal of Economics and Financial Issues. Vol. 2, No. 2, 216-224

Liu C. Y., He J. (1991), A variation ratio test of random walks in foregn exchange rate, Journl of Finance, Vol. 46, No. 2 773-785

Meesa R. A., Rogoff K. (1983), Empirical exchange rate models of the seventies. Do they fit out of sample?, Journal of international Ekonomics, Vol. 14, 3-24

Phillips P. C. B., JIN S. (2014): Testing the Martingale Hypothesis. American Statistical Association Journal of Business \& Economic Statistics. Vol. 32, No. 4. DOI: 10.1080/07350015.2014.908780

Rufino C. C. (2014): Martingale In Floating Asean+3 Currencies. DLSU Bisness \& Economics Review. Vol.23 No. 2, 65-79

Vats A., Kamaiah B. ( 2011) : Is There a Random Walk in Indian Foreign Exchange Market?. International Journal of Economics and Finance. Vol. 3, No. 6, 157-165

Yaffee R. (2000): Introduction to time series analysis and forecasting with application of SAS and SPSS; Academic Press, INC

YIImaz K. (2001): Martingale Property of Exchange Rates and Central Bank Interventions. Social science research network, http://ssrn.com/abstract=280888 
